\title{
PENGARUH KEPEMIMPINAN DAN LINGKUNGAN KERJA TERHADAP KOMITMEN ORGANISASI: PERAN MEDIASI KEPUASAN KERJA
}

\author{
EFFECT OF LEADERSHIP AND WORK ENVIRONMENT ON ORGANIZATIONAL COMMITMENT: \\ MEDIATING ROLE OF JOB SATIFICATION
}

\author{
Alvia Santoni*), Gampo Heryono*), Sudirman*), Endri" ${ }^{* * 1}$ \\ ${ }^{*}$ Sekolah Tinggi Ilmu Ekonomi Sakti Alam Kerinci \\ Jl. Jend. Sudirman No.89, Pelayang Raya, Sungai Bungkal, Kota Sungai Penuh, Jambi 37111, Indonesia \\ ${ }^{* *}$ Universitas Mercu Buana \\ Jl. Raya Meruya Selatan, Kembangan, Jakarta 11650, Indonesia
}

\begin{abstract}
This study aims to empirically prove the influence of leadership behavior and work environment on turnover intention with job satisfaction as a mediating variable. The research sample was conducted using purposive sampling technique and 128 nonmanagerial permanent employees were selected at PT. XYZ as respondent. The method for proving research hypotheses uses path analysis which can identify both direct and indirect effects and is also an indicator to test validity and reliability. The research data was processed using Partial Least Square (PLS) with SMART PLS Ver 3.0 software. The results of the study found that leadership and work environment had an effect on job satisfaction. Job satisfaction directly affects organizational commitment, while leadership and the environment indirectly through mediation of job satisfaction affect organizational commitment. Taken together, leadership, work environment, andjob satisfaction determine employee organizational commitment to the company. Suggestions from the results of the study, so that employee commitment is high to the company, management needs to change leadership styles that are adaptive and transformative, as well as a comfortable and friendly work environment that can increase job satisfaction.
\end{abstract}

Keywords: organizational commitment, leadership, work environment, job satisfaction, turnover intention

\begin{abstract}
Abstrak: Penelitian bertujuan membuktikan secara empiris pengaruh perilaku kepemimpinan dan lingkungan kerja terhadap niat berpindah dengan kepuasan kerja sebagai variabel yang memediasi. Sampel penelitan dilakukan menggunakan teknik purposive sampling dan terpilih sebanyak 128 karyawan tetap non-manajerial PT. XYZ sebagai responden. Metode untuk pembuktian hipotesis penelitian menggunakan analisis jalur yang dapat mengidentifikasi baik efek langsung maupun tidak langsung dan juga menjadi indikator untuk menguji validitas dan reliabilitas. Data penelitian diolah menggunakan Partial Least Square (PLS) dengan Perangkat lunak SMART PLS Ver 3.0. Hasil penelitian menemukan bahwa kepemimpinan, dan lingkungan kerja berpengaruh terhadap kepuasan kerja. Kepuasan kerja secara langsung berpengaruh terhadap komitmen organisasi, sementara kepemimpinan dan lingkungan secara tidak langsung melalui mediasi kepuasan kerja berpengaruh terhadap komitmen organisasi. Secara bersama-sama, kepemimpinan, lingkungan kerja, dan kepuasan kerja menentukan komitmen organisasi karyawan pada perusahaan. Saran hasil penelitian, agar supaya komitmen karyawan tinggi terhadap perusahaan, maka manajemen perlu merubah gaya kepimimpinan yang adaptif dan transformatif, serta lingkungan kerja yang nyaman dan bersahabat yang dapat meningkatkan kepuasan kerja.
\end{abstract}

Kata kunci: komitmen organisasi, kepemimpinan, lingkungan kerja, kepuasan kerja, perputaran intensi

\footnotetext{
${ }^{1}$ Corresponding author:

Email: endri@mercubuana.ac.id
} 


\section{PENDAHULUAN}

Pertumbuhan suatu industri sangat ditentukan oleh Sumber Daya Manusia (SDM), disamping investasi dan teknologi. Ketersediaan SDM industri yang kompeten dapat mendorong peningkatan produktivitas dan menjadikan industri lebih berdaya saing. Agar SDM memiliki daya saing yang kuat, diperlukan upaya untuk meningkatkan kapabilitas dan daya saing agar memudahkan mendapatkan pekerjaan pada perusahaan diberbagai sektor, baik di dalam negeri maupun luar negeri. Kemajuan suatu perusahaan sangat tergantung dari motivasi yang tinggi dari seluruh lapisan karyawan untuk dapat berpartisipasi secara aktif. Oleh karena itu, semua tingkatan karyawan merasa memiliki persepsi dan pemahaman yang sejalan ketika membantu perusahaan atau organisasi untuk bisa bertumbuh dan berkembang.

Kepemimpinan yang diperankan oleh seorang manajer dalam perusahaan dapat melakukan integrasi yang cocok dan memotivasi semangat kerja karyawan untuk meraih target yang maksimal, peran kepemimpinan harus bisa mengukuhkan loyalitas, kepercayaan, partisipasi, dan motivasi diri karyawan dengan sentuhan pibadi. Kondisi ini semua dapat diraih jika kecakapan, kemampuan dan perilakunya sesuai dengan yang diharapkan (Riyanto et al. 2021; Al-Amin, 2017). Kepemimpinan mempunyai pengaruh yang parsial terhadap Kepuasan Kerja. Gaya kepemimpinan dapat menyesuaikan dengan situasi dan kondisi, sehingga dapat ditentukan langkah-langkah perbaikan untuk lebih memacu tingkat kepuasannya (Hapsari et al. 2021)

Faktor lain yang memengaruhi kepuasan kerja karyawan adalah lingkungan kerja. Lingkungan kerja merupakan kondisi aktual yang dimiliki perusahaan berupa keseluruhan sarana dan prasarana kerja yang terdapat di sekitar tempat kerja pegawai yang dapat memengaruhi pencapaian hasil kerja. Lingkungan kerja mencakup antara lain; tempat bekerja, fasilitas dan alat bantu pekerjaan, kebersihan, pencahayaan, kenyamanan, dan suasana bathin hubungan kerja antar karyawan yang berada dalam satu perusahaan tempat mereka bekerja (Duru dan Shimawua, 2017).

Besarnya keinginan karyawan untuk meninggalkan perusahaan ditentukan oleh kepuasan kerja mereka didalam perusahaan, turnover intention dapat ditekan dengan upaya meningkatkan kepuasan kerja karyawan didalam perusahaan. Kepemimpinan dan lingkungan kerja merupakan sebagian dari faktor-faktor yang dapat mempengaruhi kepuasan kerja. Michael (2006) menguraikan perputaran intensi adalah peluang yang bersifat subyektif dimana seorang individu berencana merubah pekerjaannya dalam jangka waktu tertentu dan merupakan pendorong kuat melaukan perputaran intensi yang sebenarnya.

Penelitian Shahab dan Nisa (2014) menyatakan ada hubungan yang signifikan antara kepemimpinan dan kepuasankerjakaryawan, dimanadengankepemimpinan yang efektif dan strategik dapat meningkatkan semangat kerja. Selanjutnya studi Ali et al. (2014) menyimpulkan bahwa kesuksesan kerja dalam lingkungan industri yang cepat berubah, manajemen perusahan sektor otomotif dapat mengadopsi gaya kepemimpinan transformasional yang bertentangan dengan gaya kepemimpinan tradisional. Ini dapat berkontribusi pada tingkat kepuasan kerja karyawan yang konsisten dan ditingkatkan dan akibatnya kinerja karyawan berkualitas lebih tinggi.

Penelitian Sakthivel dan Jayakrishnan, (2012) mengemukakan bahwa keseimbangan hidup kerja berperan penting dalam meningkatkan kinerja dan komitmen organisasi. Lingkungan kerja yang positif dapat memberikan kepuasan kepada karyawan untuk tetap berkomitmen terhadap pekerjaan mereka. Penelitian Tolentino (2013) membuktikan bahwa hubungan atasan dan bawahan ditempat kerja dapat menentukan kepuasan kerja. Hubungan atasan-bawahan yang baik tidak hanya berdampak terhadap kepuasan kerja, tetapi juga memperluas pengaruh efektifitas terhadap kepuasan kerja. Manajer perlu dilatih untuk menjadi lebih mendukung dan membangun hubungan timbal balik dengan bawahan mereka untuk menjadi lebih erat, yang akan berdampak pada peningkatan kepuasan kerja karyawan.

Penelitian Lee(2017)menemukanbahwakepuasan kerja karyawan dipengaruhi oleh perlakuan yang sama pada pekerja di tempat dan lingkungan kerja, seta pelayanan. Keadaan ini menjadikan karyawan menyadari bahwa mereka tidak diperlakukan berbeda dibawah arahan pimpinan yang bertanggung jawab dengan baik, sehingga karyawan tidak memiliki keinginan untuk berpindah pekerjaan ke perusahaan lain. Chen (2006) membuktikan bahwa dengan supervisi atasan dapat meningkatkan kepuasan kerja karyawan sehingga dapat menciptakan kesetiaan karyawan dan komitmen yang tinggi pada perusahaan tempat mereka bekerja 
Penelitian Chen et al. (2011) menemukan pengaruh seringnya pergantian kepemimpinan terhadap turnover intentiondengandimoderasiolehperilakukepemimpinan etis. Kepemimpinan tidak secara langsung berpengaruh terhadap turnover intention, kepemimpinan dengan di moderasi gaya kepemimpinan mempengaruhi turnover intention. Penelitian Sundi (2015) mengemukakan peran penting dari pemimpin pada perilaku karyawan, dimana karyawan yang kecewa akan memiliki sikap negatif terhadap pekerjaannya dan punya niat besar untuk keluar dari pekerjaan

Pergantian sosok pemimpin tidak memiliki pengaruh langsung terhadap turnover intention, ditemukan bahwa kepemimpinan melalui kepuasan kerja mempengaruhi turnover intention. Penelitian Paracha (2012), menyatakan bahwa meningkatkan fasilitas pendukung di tempat kerja bisa menjadi sumber utama untuk menjaga lingkungan yang positif dan mengurangi turnover intention. Selanjutnya dalam penelitian Kertabudi dan Aripin (2015) menemukan bahwa lingkungan tempat kerja menjadi faktor penting untuk menjaga agar karyawan tetap bertahan. Penelitian menyimpulkan bahwa hasrat berpindah karyawan dapat berkurang jika lingkungan tempat kerja mereka nyaman dan bersih. Dengan fenomena yang telah diungkapkan, studi bertujuan membuktikan secara empiris pengaruh kepemimpinan dan Lingkungan kerja terhadap turnover intention (komitmen organisasi) dengan peran kepuasan kerja sebagai mediasi

\section{METODE PENELITIAN}

Objek penelitian adalah perusahaan XYZ yang bergerak pada bidang jasa. Metode pengambilan sampel menggunakan nonprobability sampling dengan teknik sampling purposive, yaitu teknik penentuan sampel dengan pertimbangan tertentu, maka terpilih sebanyak 128 karyawan tetap non-manajerial PT. XYZ sebagai responden.

Metode untuk pembuktiaan hipotesis penelitian menggunakan analisis jalur yang dapat mengidentifikasi baik efek langsung maupun tidak langsung dan juga menjadi indikator untuk menguji validitas dan reliabilitas. Data penelitian diolah menggunakan Partial Least Square (PLS) dengan Perangkat lunak SMART PLS Ver 3.0. Penelitian menggunakan data primer yang diperoleh secara langsung dari resonden yang menjadi objek sumber informasi. Data responden dikumpulkan menggunakan teknik survei melalui kuisioner. Kuesioner disusun berdasarkan beberapa referensi yang menjadi rujukan, yang selanjutnya disesuaikan dengan format pertanyaan, kemudian untuk mengidentikasi pendapat, persepsi, dan sikap responden digunakan Skala Likert. Langkah awal dilakukan uji validitas dan realibilitas terhadap instrumen penelitia sebelum kuesioner disampaikan kepada responden.

Penelitian ini diklasifikasi sebagai riset eksploratif dengan pendekatan kuantitatif. Metode riset eksploratif adalah jenis penelitian yang bertujuan membahas posisi variabel-variabel yang diuji serta pengaruh antara satu variabel dengan variabel yang lain. Berdasarkan kepada tingkat penjelasan, maka jenis penelitian ini adalah penelitian asosiatif yang bertujuan untuk menganalisis pengaruh sekelompok variabel sebagai faktor penentu terhadap variabel lain sebagai faktor tujuan melalui serangkaian pengujian hipotesis. Pada penelitian ini peneliti berusaha menjelaskan keterkaitan antar variabel kepemimpinan (X1), Lingkungan Kerja, Turnover Intention (Y) dan kepuasan kerja (Z).

\section{HASIL}

Mengacu pada Tabel 1 indikator disebut valid jika nilai peluang lebih kecil dari 0,05 dan hasil composite reability maupun cronbach alpha diperoleh angka sebesar 0,7 untuk variabel kepemimpinan, lingkungan kerja, komitmen dan kepuasan kerja secara individual. Kondisi ini mengindikasikan instrumen yang diujikan memiliki konsistensi dan stabilitas tinggi.

Mengacu pada Tabel 2, diperoleh nilai $\mathrm{R}^{2}$ sebesar 0.566 untuk kepuasan kerja, halinimenunjukkan bahwa 56,6\% variasi atau perubahan Kepuasan kerja dipengaruhi oleh variabel kepemimpinan dan lingkungan kerja. Dengan demikian maka hasil perhitungan $\mathrm{R}^{2}$ Kepuasan Kerja menunjukkan bahwa $\mathrm{R}^{2}$ termasuk moderat.

Nilai $\mathrm{R}^{2}$ Komitmen Organiasi sebesar 0.560 , yang menunjukkan bahwa $56 \%$ variasi atau perubahan Komitmen Organiasasi Intention dipengaruhi oleh variabel kepemimpinan, lingkungan kerja dan kepuasan kerja sedangkan sisanya sebanyak $44 \%$ dijelaskan oleh sebab lain. Dengan nilai $\mathrm{R}^{2}$ Turnover Intention yang diperolah maka dikatakan bahwa koefisien diterminasi tergolong moderat. 
Tabel 1. Rangkuman outer model

\begin{tabular}{|c|c|c|c|c|c|}
\hline Model Pengukuran & Variabel & \multicolumn{2}{|c|}{ Hasil } & Nilai Kritis & Keterangan \\
\hline Validitas & Kepemimpinan & \multicolumn{2}{|c|}{0,00} & $<0,05$ & Valid \\
\hline Convergent Validity & Lingkungan Kerja & \multicolumn{2}{|c|}{0,00} & $<0,05$ & Valid \\
\hline$A V E$ & Kepuasan Kerja & \multicolumn{2}{|c|}{0,00} & $<0,05$ & Valid \\
\hline Discriminat Validity & Komitmen & \multicolumn{2}{|c|}{0,00} & $<0,05$ & Valid \\
\hline Reliabilitas & Kepemimpinan & 0,963 & 0,956 & $>0,7$ & Reliable \\
\hline Composite Realibilty & Lingkungan Kerja & 0,942 & 0,935 & $>0,7$ & Reliable \\
\hline \multirow[t]{2}{*}{ Cronbach Alpha } & Kepuasan Kerja & 0,914 & 0,893 & $>0,7$ & Reliable \\
\hline & Komitmen & 0,946 & 0,938 & $>0,7$ & Reliable \\
\hline
\end{tabular}

Tabel 2. Rangkuman inner model

\begin{tabular}{lcclc}
\hline Variabel & $\mathrm{R}^{2}$ & $\mathrm{Q}^{2}$ & \multicolumn{2}{c}{ F2 } \\
\hline Kepuasan Kerja & 0,566 & $81 \%$ & Kepemimpinan $\rightarrow$ Kepuasan Kerja & 0,392 (kuat) \\
& & & Kepemimpinan $\rightarrow$ Turnover Intention & 0,026 (lemah) \\
Turnover intenton & 0,560 & & Kepuasan Kerja $\rightarrow$ Turnover Intention & 0,173 (sedang) \\
& & & Lingkungan Kerja $\rightarrow$ Kepuasan Kerja & 0,123 (sedang) \\
& & & Lingkungan Kerja $\rightarrow$ Turnover Intention & 0,085 (lemah) \\
\hline
\end{tabular}

Dari hasil F-Square dapat disimpulkan bahwa peran kepemimpinan terhadap kepuasan kerja tergolong kuat. Kepemimpinan terhadap komitmen dan lingkungan kerja tidak kuat, sedangkan kontribusi kepuasan kerja terhadap komitmen, dan lingkungan kerja terhadap kepuasan kerja kategorinya sedang.

Tabel 3 menunjukkan rangkuman keterkaitan variabel dengan dimensi penelitian. Koefisien jaur tertingi sebesar 4,091 menyatakan bahwa hubungan kuat antara dimensi Pelanggaran kerja Lingkungan Kerja Fisik, artinya dengan lingkungan kerja fisik yang tidak fisik dapat meningkatkan peluang bagi karyawan melakukan pelanggaran kerja. Untuk nilai koefisien jalur terkecil terjadi antara dimensi Supervisi Atasan da Kecerdasan Kepemimpinan, artinya menunjukkan hubungan yang biasa antara supervisi atasan dengan kecederdasan Kepemimpinan.

Hasil uji antar variabel penelitian ditunjukkan dalam tabel 4. Berdasarkan nilai koefisien jalur terdapat empat hubungan antar variabel yang signifikan dengan $\alpha=$ $5 \%$, yaitu hubungan kepemimpinan dengan kepuasan kerja, kepuasan kerja dengan komitmen organisasi, lingkungan kerja dengan kepuasan kerja dan lingkungan kerja dengan komitmen organisasi. Hubungan yang kuat antar variabel dengan nilai koefisien jalur sebesar 0,531 yang berari bahwa kepemimpinan memiliki keterkaitan searah dengan kepuasan kerja, sementara nilai koefisien jalur terkecil dengan angka sebesar 0,160 dengan tanda negatif dapat diinterprestasikan bahwa hubungan kepemimpinan berlawanan yang kurang kuat dengan komitmen.

Tabel 5 menunjukkan ringkasa peran kepuasan kerja sebagai variabel moderasi pengaruh kepemimpinan dan lingkungan kerja terhadap komitmen organisasi. Berdasarkan uji statistik dengan $\alpha=5 \%$, menyimpulkan bahwa peran kepuasan kerja memediasi variabel kepemimpinan dan linkungan kerja berpengaruh secara signifikan terhadap turnover intention. Hal ini juga dapat dikatakan bahwa agar komitmen karyaran yang tinggi pada perusahaan dan menekan keinginan mereka untuk berhenti dari tempat mereka bekerja, maka kepuasan kerjanya harus ditingkatkan melalui model kepempiminan yang adaptif dan transformatif serta lingkungan kerja yang nyaman dan kondusif.

\section{Pengaruh Kepemimpinan Terhadap Kepuasan Kerja}

Berdasarkan temuan empiris menunjukkan bahwa kepemimpinan menentukan kepuasan kerja, dimana dengan kepemimpinan yang lebih baik mampu meningkatkan kepuasan kerja karyawan. Temuan empiris mendukung studi Hakkak et al. (2017) yang menyimpulkan bahwa kepemimpinan yang dominan dapat memengarhi kepuasan dan kesetiaan kerja. 
Tabel 3. Rangkuman hasil uji path coefficients variabel

\begin{tabular}{|c|c|c|c|c|c|c|c|}
\hline \multirow{2}{*}{$\frac{\text { Variabel }}{\text { Dimensi }}$} & \multicolumn{2}{|c|}{ Kepemimpinan } & \multicolumn{2}{|c|}{ Lingkungan Kerja } & \multicolumn{3}{|c|}{ Kepuasan Kerja } \\
\hline & Kecerdasan & $\begin{array}{c}\text { Motivasi } \\
\text { Diri }\end{array}$ & Fisik & Non Fisik & Pekerjaan & $\begin{array}{c}\text { Supervisi } \\
\text { Atasan }\end{array}$ & Promosi \\
\hline \multicolumn{8}{|l|}{ Kepusan Kerja } \\
\hline Supervisi Atasan & 2,026 & 2,541 & - & - & - & - & - \\
\hline Imbalan & - & - & - & - & - & - & - \\
\hline Rekan Kerja & - & - & - & 2,237 & - & - & - \\
\hline \multicolumn{8}{|c|}{ Komitmen Organisasi } \\
\hline Absensi & - & - & 2,241 & - & 2,719 & - & 3,151 \\
\hline Malas Bekerja & - & - & 4,932 & - & - & 2,368 & 3,606 \\
\hline Pelanggaran & - & - & 4,091 & - & - & - & 2,428 \\
\hline Protes & - & - & 2,132 & - & - & - & - \\
\hline Perilaku & - & - & 2,241 & - & - & - & - \\
\hline
\end{tabular}

Tabel 4. Hasil uji antar variabel

\begin{tabular}{lcccc}
\hline Variabel & Koef. Jalur & T-stat & P-val. & Hasil \\
\hline Kepemimpinan $\rightarrow$ Kepuasan Kerja & 0,531 & 6,545 & 0,000 & Sig. \\
Kepemimpinan $\rightarrow$ Komitmen Organisasi & $-0,160$ & 1,519 & 0,131 & No-Sig. \\
Kepuasan Kerja $\rightarrow$ Komitmen Organisasi & $-0,418$ & 3,623 & 0,000 & Sig. \\
Lingkungan Kerja $\rightarrow$ Kepuasan Kerja & 0,298 & 3,343 & 0,002 & Sig. \\
Lingkungan Kerja $\rightarrow$ Komitmen Organisasi & $-0,262$ & 2,683 & 0,000 & Sig. \\
\hline
\end{tabular}

Tabel 5. Ringkasan uji variabel intervening

\begin{tabular}{lcccc}
\hline Variabel & Original Sample & $\mathrm{T}$-Stat & P-Val. & Ket. \\
\hline $\begin{array}{l}\text { Kepemimpinan } \rightarrow \text { Kepuasan Kerja } \rightarrow \text { Komitmen } \\
\text { Organisasi }\end{array}$ & $-0,223$ & 2,881 & 0,003 & Mediasi parsial \\
$\begin{array}{l}\text { Lingkungan Kerja } \rightarrow \text { Kepuasan Kerja } \rightarrow \text { Komitmen } \\
\text { Organisasi }\end{array}$ & $-0,123$ & 2,702 & 0,006 & Mediasi parsial \\
\hline
\end{tabular}

Penelitian Yunus dan Ahmad (2013) juga membuktilan pengaruh kepemimpinan terhadap kepuasan kerja. Studi Virgiawan et al. (2021), Andri et al. (2011), Fatima et al. (2011), dan Rehman et al. (2012) juga mengkonfirmasi hasilpenelitianbahwakepemimpinanmemilikipengaruh kuat dan berpengaruh positif terhadap kepuasan kerja. Dimensi kecerdasaan, kematangan sosial, motivasi dan sikap hubungan manusiawi yang dimiliki seorang pemimpin mampu memberikan pengaruh terhadap peningkatan kepuasan kerja. Seorang pemimpin juga harus mampu menunjukan kemampuan daya pikir kreatif dan inovatif dalam membantu bawahannya untuk menyelesaikan permasalahan yang dihadapi serta perhatian yang tinggi untuk memotivasi bawahan untuk menjadi lebih baik dan menciptakan hubungan manusiawi antara pimpinan dan bawahannya. Semua kondisi tersebut menciptakan kepuasan kerja.
Hasil penelitian Voon et al. (2001) membuktikan penurunan tingkat kepuasan kerja karyawan yang bekerja dengan manajer yang memiliki kharateristik kepemimpinan interaksional. Sebaliknya penelitian Bass (1990) mengungkapkan bahwa pemimpin dengan tipe transformasional berkorelasi kuat dengan kepuasan kerja. Bass (1990) mengungkapkan bahwa kepemimpinan transformasional menjadi sosok yang mampu mendorong, menginspirasi, dan menjadikan karyawannya merasa nyaman bekerja dengan pimpinannya dan menaikkan kepuasan kerja karyawan. Temuan Aamodt (2007) menyatakan jika karyawan bisa bekerja dengan nyaman bersama pimpinannya maka dapat menaikkan kepuasan kerja. Penelitian Emery dan Barker (2007) menyatakan bahwa kepemimpinan berperan terhadap kepuasan kerja karyawan, dimana kepemimpinan transformasional mampu memberikan kepuasan kerja lebih baik dibandingkan kepemimpinan 
transaksional. Keadaan membuktikan bahwa pemimpin memiliki peran untuk ikut meningkatkan rasa kepuasan kerja karyawan dalam suatu perusahaan. Studi Rad dan Yarmohammadin (2006) menyatakan bahwa kepuasan kerja karyawan dipengaruhi oleh kepemimpinan. Penelitian tersebut menyatakan bahwa karyawan dengan pemimpin lebih partisipatif memiliki kepuasan yang lebih tinggi.

Studi Ahmad et al. (2013) membuktikan hubungan yang erat antara kepuasan kerja dan kepemimpinan transformasional dibandingkan dengan kepemimpinan transaksional. Ada juga efek yang berbeda antara kepemimpinan transformasional dan kepemimpinan transaksional pada kepuasan kerja. Kepemimpinan transformasional memiliki rasio dan beta yang lebih tinggi yang menunjukkan pengaruh lebih tinggi pada kepuasan kerja dibandingkan dengan kepemimpinan transaksional. Di sini, hasil ini lebih lanjut mendukung studi dari Tale (2010), di mana ada hubungan antara modelkepemimpinantransformasional dantransaksional pada kepuasan kerja. Namun, kepemimpinan transformasional adalah model kepemimpinan dominan yang dapat memengaruhi kepuasan kerja perawat. Dalam penelitian lain sebelumnya, kedua model kepemimpinan juga telah ditunjukkan memiliki efek pada kepuasan kerja tetapi menurut analisis yang dilakukan, model kepemimpinan transformasional ditemukan berperilaku hasil kepemimpinan yang lebih tinggi dibandingkan dengan kepemimpinan transaksional (Limsila dan Ogunlana, 2007).

\section{Pengaruh Kepemimpinan Terhadap Turnover Intention}

Hasil penelitian menunjukan bahwa kepemimpinan tidak mampu memengaruhi turnover intention, yang berarti perubahan kapabilitas kepemimpinan perusahaan tidak dapat merubah turnover intention karyawan. Kapabilitas kepemimpinan merupakan kemampuan yang dimiliki oleh seorang pemimpin dalam mengelola organisasi dan sumber daya. Temuan empiris sejalan dengan penelitian Xiancheng (2010) yang mengemukakan pergantian sosok pemimpin secara tidak langsung berpengaruh terhadap turnover intention, ditemukan bahwa kepemimpinan melalui kepuasan kerja mempengaruhi turnover intention. Penelitian Awan dan Mahmood (2010) menemukan model kepemimpinan tidak memberikan pengaruh turnover intention secara langsung, yang berarti bahwa dengan memperbaiki model kepemimpinan dan tidak dengan sendirinay berpengaruh terhadap penurunan turnover intention.

Hasil penelitian berbeda diungkap oleh Saklit (2017) yang menyatakan bahwa model kepemimpinan mampu memengaruhi secara positif terhadap turnover intention baik secara langsung maupun melalui kepuasan kerja. Studi Wahyuni et al. (2014) membuktikan hubungan pekerja dan pimpinan perusahaan jasa konstruksi dapat meningkatkan komitmen organisasi, hal ini berarti bahwa untuk perusahaan-perusahaan tertentu gaya kepemimpinan tidak memberikan pengaruh negatif terhadap turnover intention, sehingga bisa dinyatakan bahwa dengan meningkatnya gaya kepemimpinan yang dirasakan pekerja tidak selalu mampu menurunkan tingkat turnover intention karyawannya, walaupun dengan meningkatnya gaya kepemimpinan akan menaikkan pula kepuasan kerja yang dirasakan pekerja.

\section{Pengaruh Kepuasan Kerja Terhadap Turnover Intention}

Temuan empiris membitikan bahwa kepuasan kerja berdampak terhadap turnover intention, yang memiliki arti bahwa kepuasan kerja karyawan yang lebih tinggi memberikan dampak peningkatan turnover intention. Temuan penelitian ini konsisten dengan studi Gul et al. (2012) yang membuktikan bahwa kepuasan kerja merupakan faktor yang berperan penting terhadap komitmen organisasi karyawan diantaranya adalah sifat pekerjaan, pengembangan karir, pengawasan dan gaji. Temuan juga membuktikan ketidakpuasan bekerja turut menyumbang hasrat karyawan untuk berpindah kerja ditempat lain. Penelitian Long et al. (2012) membuktikan bahwa kepuasan kerja dapat menentukan komitmen organisasi, misalnya dengan dengan menaikkan gaji, memberikan respon perhatian yang terfokus pada keinginan dan memahami perasaan karyawan terhadap pekerjaan yang mereka lakukan.

Berdasarkan model teoritis Maslow dan Helzberg, kepuasan kerja adalah fungsi dari berbagai kebutuhan terpenuhi (Maslow, 1954). Pada dasarnya, ketika kebutuhan spesifik terpenuhi, organisasi dapat berharap bahwa karyawan dapat mengalami tingkat kepuasan kerja yang tinggi. Model turnover Maret dan Simon menjadi dasar bagi keputusan karyawan memulai bekerja dipengaruhi oleh kemudahan yang dirasakan 
dan keinginan untuk bergerak, yang dapat dipicu oleh kepuasan kerja (Morrell, 2001). Tidak jauh berbeda dengan model turnover Mobley's menunjukkan bahwa ketika seorang karyawan tidak puas dengan pekerjaannya, maka ia kemudian berhenti bekerja jika pekerjaan baru diharapkan memberikan kepuasan yang lebih tinggi (Mobley, 1977).

\section{Pengaruh Lingkungan Kerja Terhadap Kepuasan Kerja}

Temuan empiris membuktikan bahwa kepuasan kerja dipengaruhi oleh lingkungan kerja yang memiliki arti bahwa dengan lingungan kerja yang nyaman dapat meningkatkan kepuasan kerja karyawan. Hasil penelitian konsisten dengan temuan Abu et al. (2016) yang membuktikan bahwa lingkungan tempat bekerja yang kondusif dapat menciptakan suasana kerja nyaman bagi karyawan dan menimbulkan komitmen yang tinggi untuk bertahan ditempat mereka bekerja. Penelitian lainnya dari Malik et al. (2016) menemukan bahwa kepuasan kerja karyawan meningkat jika lingkungan kerja mereka baik. Hal ini menunjukkan bahwa semakin karyawan merasa bahwa lingkungan kerjanya semakin baik dapat meningkatkan kepuasan kerja yang dirasakan oleh karyawan, sementara lingkungan fisik dan nonfisik sangat berpengaruh dalam aktifitas pekerjaan. Lingkungan yang langsung berhubungan dengan karyawan dan lingkungan umum yang terawat dan diperhatikan standarnya serta kondisi hubungan antara pekerja berpengaruh terhadap tingkat kepuasan kerja. Dengan prosedur kerja yang lengkap dan jelas disertai dengan peralatan kerja yang mendukung dapat memberikan kenyaman dan keamanan bagi karyawan dalam berkerja.

Chandrasekar (2011) mengemukan bahwa suatu organisasi perlu untuk menciptakan lingkungan kerja yang baik untuk meningkatkan kemampuan karyawan supaya menjadi lebih produktif dalam menghasilkan laba bagi organisasi. Disamping itu, Interaksi antar manusia berperan besar dalam kepuasan kerja secara keseluruhan daripada uang sedangkan keterampilan manajemen, waktu dan energi, semua dibutuhkan untuk meningkatkan keseluruhan kinerja organisasi di era saat ini. Sell dan Bryan (2011) mengembangkan model kepuasan kerja dengan mengintegrasikan variabel ekonomi dan variabel lingkungan kerja untuk mempelajari reaksi karyawan di lingkungan kerja berbahaya dengan manfaat moneter yang besar dan lingkungan kerja yang tidak berbahaya dengan manfaat moneter yang rendah. Hasil penelitian menunjukkan hal yang berbeda variabel psikososial dan lingkungan kerja seperti; hubungan sosial berdampak terhadap kepuasan kerja, dan kenaikan balas jasa tidak menaikkan tingkat ketidakpuasan di antara karyawan.

\section{Pengaruh Lingkungan Kerja Terhadap Turnover Intention}

Temuan empiris menyimpulkan bahwa lingkungan kerja berdampak terhadap komitmen organisasi yang berarti bawah suasana lingkungan tempat bekerja yang baik dapat menurunkan turnover intention karyawan ketingkat yang rendah. Karyawan dapat memobilisasi semua kemampuan dan kreativitas mereka jika didukung oleh lingkungan kerja yang baik. Namun, jika lingkungan tempat bekerja tidak nyaman bagi karyawan, maka mengakibatkan mereka tidak betah dalam perusahaan dan intensi turnover menjadi tinggi. Temuan ini relevan dengan studi yang dikemukakan oleh Shah et al. (2012) bahwa salah satu faktor yang menyebabkanturnover tinggidi suatu perusahaanadalah komunikasi di tempat kerja, lingkungan politik, rekan kerja dan sikap atasan yang membuat karyawan merasa tidak puas di tempat kerja. Penelitian Hamstra et al. (2011) juga mengungkapkan bahwa lingkungan tempat kerja menjadi penentu dominan untuk mempertahankan karyawan. Penelitian juga mengungkapkan bahwa lingkungan tempat bekerja yang nyaman dan bersih dapat menekan keinginan berpindah. Studi Hancock et al. (2013) menemukan lingkungan kerja dapat menentukan komitmen organisasi. Oleh karena itu, lingkungan kerja perusahaan yang lebih nyaman dan kondusif dapat meningkatkan komitmen karyawan.

Bukti empiris didukung oleh studi Mobley (1977) bahwa niat berpinda ditentukan oleh banyak faktor, diantaranya adalah lingkungan kerja. Lingkungan kerja dapat berbentuk penerangan atau pencahayaan yang baik dan merata, jumlah ventilasi udara yang cukup dan mampu menjalankan fungsinya dengan baik, dapat menciptakan tata warna yang selaras dengan tempat kerja, nyaman dan bersih, terjaga saling komunikasi yang baik atasan dan pekerja, sesama pekerja, dan saling membantu antar pekerja di tempat mereka bekerja. Temuan yang serupa juga diungkap oleh penelitian Vizano et al. (2021), Yunita (2015), dan Halimah (2016) yang menyatakan bahwa lingkungan kerja pekerja berpengaruh terhadap turnover intention. 


\section{Implikasi Manajerial}

Implikasi manajerial hasil penelitian terhadap model pimpinan perusahaan dengan karakter cerdas, kepedulian sosial, motivasi dan sikap hubungan manusiawi merupakan syarat yang objektif bagi perusahaan untuk mencapai tujuan organisasi. Kemampuan pemimpin PT. XYZ diharapkan dapat memenuhi syarat-syarat tersebut agar karyawan dapat mencapai kepuasan kerja dan mengurangi niat untuk berhenti dari perusahaan. Dimenasu lingkungan Kerja baik fisik maupun non-fisik diharapkan bagian dari strategi PT. XYZ yang menjadi pedoman dan ditingkatkan agar karyawan senantiasa merasa nyaman dan tenang untuk beraktivitas dalam pekerjaannya. Perbaikan lingkungan kerja dapat dilakukan, antara lain dengan; menguransi potensi bahaya yang ada, ciptakan komunikasi yang baik, pengaturan area kerja yang kondusif, dan penerangan dan cuaca yang sejuk. Kepuasan Kerja, terutama pada dimensi kesempatan promosi merupakan hal yang menjadi perhatian. Dengan demikian, manajemen perusahaan harus memberikan penjelasan yang lebih detail agar setiap karyawan memahami perencanaan karir yang telah di siapkan manajemen. Oleh karena itu, tantangan pekerjaan yang diberikan dapat di laksanakan dengan semaksimal mungkin oleh karyawan.

\section{KESIMPULAN DAN SARAN}

\section{Kesimpulan}

Berdasarkan temuan empiris membuktikan bahwa model kepemimpinan manajemen perusahaan dan lingkungan tempat bekerja dapat meningkatkan kepuasan kerja. Kepuasan kerja berpengaruh negatif terhadap komitmen organisasi, sementara kepemimpinan tidak berpengaruh terhadap komitmen orgamisasi. Lingkungan kerja berpengaruh negatif terhadap komitmen orgamisasi. Secara keseluruhan, kepemimpinan, lingkungan kerja dan kepuasan kerja dapat menentukan komitmen organiasi bagi karyawan

\section{Saran}

Penelitian memiliki keterbasan terutama terkait dengan faktor yang memengaruhi komitmen organiasi melalui mediasi kepuasan kerja karyawan. Saran penelitian yang kedepan, bisa mempertimbangakan faktor lain, misalnya; agama, sosial, pendidikan, dan insentif

\section{DAFTAR PUSTAKA}

Al-Amin Md. 2017. Transformational leadership and employee performance mediating effect of employee engagement. North South Business Review 7(2): 28-40.

Aamodt MG. 2007. Industrial Organizational Psycology an Aplied Approach, 5th ed. USA: Thomson Wodsworth.

Abu Al-Rub R, El-Jardali F, Jamal D, Abu Al-Rub N. 2016. Exploring the relationship between work environment, job satisfaction, and intent to stay of Jordanian nurses in underserved areas. Applied Nursing Research 31:19-23. https://doi. org/10.1016/ j.apnr.2015.11.014.

Ahmad AR, Adi MNM, Noor H Md, Rahman AGR, Yushuang T. 2013. The Influence of Leadership Style on Job Satisfaction among Nurses. Asian Social Science 9( 9): 172-178.

Ali N, Ali S, Ahsan A, Rahman W, Kakakhel S J. 2014. Effet of leadership styles on job satisfaction, OCB, commitment and turnover intention: Empirical study of private sector school's teacher. Life Science Journal 11(35): 175-183.

Andri S, Troena EA, Idrus, Djumahir. 2011. Pengaruh Gaya Kepemimpinan, Budaya Organisasi, Motivasi, Program Diklat terhadap Kinerja dan Kepuasan Kerja Karyawan pada PT. Telkom Tbk Pekanbaru. Jurnal Aplikasi Manajemen 9(4): 1346-1355.

Awan MR, Mahmood K. 2010. Relationship among leadership style, organizational culture and employee commitment in university libraries. Journal of Library Management 31(4/5): 253266.

Bass BM, Avolio. 1990. The Implications of Transaksional and Transformational. Team and Organization Development 4: 231-273.

Chandrasekar K. 2011. Workplace Environment and Its Impact Organizational Performance in Public Sector organizations. International Journal of Enterprise Computing and Business Systems 1(1): $1-19$

Chen CF. 2006. Job satisfaction, organizational commitment, and flight attendants' turnover intentions: A note. Journal of Air Transport Management 12: 274-276.

Emery CR, Barker KJ. 2007. The Effect Of Transaksional And Transformasional Leadership Styles On The Organizational Commitment And Job Satisfaction of customer Contact Personnel. 
Journal of Organization Culture, Communication and Conflict 11(1): 7

Fatima B, Ahmad U, Asvi, N. 2011. Effect of Transformational Leadership on Employees' Job Satisfaction and Organizational Commitment in Banking Sector of Lahore (Pakistan). International Journal of Business and Social Sciences 2(18): 261-266.

Gul S, Ahamd B, Rehman SU, Shabir N, Razzaq N. 2012. Leadership styles, turnover intentions and the mediating role of organizational commitment. Journal of Information and Knowledge Management 2(7): 44-51.

Halimah TN. 2016. Pengaruh Job Insecurity, Kepuasan Kerja, dan Lingkungan Kerja Terhadap Turnover Intention Pramuniaga di Galael Supermarket (Studi Kasus pada Galael Superindo Kota Semarang). Journal of Management 2(2): 1-16.

Hakkak M, Gashti MAH, Nawaser K. 2017. The Relationship between Perceived Organizational Support \& Job Satisfaction with Organizational Commitment. Entrepreneurship and Innovation Management Journal 2(3): 194-202.

Hamstra MRW, van Yperen NW, Wisse B, Sassenberg K. 2011. Transformational transactional leadership styles and followers regulatory focus: Fit reduces follower's turnover intentions. Journal of Personnel Psychology 10(4):182-186.

Hancock J, Allen D, Bosco F, McDaniel K, Pearce C. 2013. Meta-analytic review of employee turnover as a predictor of firm performance. Journal of Management 39: 573-603.

Hapsari, D., Riyanto, S. \& Endri, E. (2021). The Role of Transformational Leadership in Building Organizational Citizenship: The Civil Servants of Indonesia. Journal of Asian Finance, Economics, and Business, 8(2), 595-604.

Lee H. 2017. A Study of Job Satisfaction, Organizational Commitment and Turnover Intention Influenced for Nano-Convergence Employees. International Journal of Applied Engineering Research 12(24): 15358-15362.

Kertabudi IS, Aripin. 2015. Effect organizational commitment and job satisfaction on employees performance at Cibabat Hospital, Cimahi City West Java. Australian Journal of Basic and Applied Science 9(33): 346-351.

Limsila K, Ogunlana SO. 2008. Performance and leadership outcome correlates of leadership style and subordinate commitment. Engineering, Construction and Architectural
Management 15(2):164-184. http://dx.doi. org/10.1108/09699980810852682.

Long CS, Thean LY, Wan Ismail WK, Jusoh A. 2012. Leadership styles and employees' turnover intention: Exploratory study of academic staff in a Malaysia college. World Applied Sciences Journal 19(4): 575-581.

Malik MI, Ahmad A, Gomez SF, Ali M. 2011. A study of work environment and employees' performance in Pakistan. African Journal of Business Management 5(34): 13227-13232. https://doi.org/ 10.5897/AJBM11.1502

Maslow AH. 1954. Motivation and Personality; Harper \& Row: New York, NY, USA.

Mobley WH. 1977. Intermediate linkages in the relationship between job satisfaction and employee turnover. J. Appl. Psychol 62:237240.

Morrell K, Loan-Clarke J, Wilkinson A. 2001. Unweaving leaving: The use of models in the management of employee turnover. Int. J. Manag. Rev 3: 219-244

Paracha MU, Qamar A, Mirza A, Hassan I, Waqas H. 2012. Impact of leadership style transformational \& transactional leadership on employee performance \& mediating role of job satisfaction: Study of private school (educator) In Pakistan. Global Journal of Management and Business Research 12(4): 55-65.

Rad AMM, Yarmohammadian MH. 2006. A study of relationship between managers' leadership style and employees' job satisfaction. Leadership in Health Services 19(2): 11-28. http://dx.doi. org/10.1108/13660750610665008.

Rehman K, Naveed S, Abdul SK, Nawaz A. 2012. Impacts of Job Satisfaction on Organizational Commitment: A Theoretical Model for Academicians in HEI of Developing Countries like Pakistan.International Journal of Academic Research in Accounting. Finance and Management Science 3(1): 80-89.

Riyanto S, Endri E, Herlisha N. 2021. Effect of work motivation and job satisfaction on employee performance: Mediating role of employee engagement. Problems and Perspectives in Management 19(3): 162-174. doi:10.21511/ ppm.19(3).2021.14

Saklit IW. 2017. Pengauh Gaya Kepemimpinan dan Pengembangan Karir terhadap Intensi Turnover: Kepuasan Kerja Sebagai Mediator. Jurnal Manajemen 21(3): 472-490. 
Sakthivel D, Jayakrishnan J. 2012. Work Life Balance and Organizational Commitment for Nurses. Asian Journal of Business and Management Sciences 2(5): 01-06.

Shah MAA, Qureshi MI, Shah H. 2012. Impact of socio economic status (SES) of family on the academic achievements of students. Gomal University Journal of Research 28(1): 12-17.

Sell L, Bryan C. 2011. Job Satisfaction, Work Environment, and Rewards: Motivational Theory Revisitedlabr. LABOUR 25(1): 1-23

Tale SM. 2010. Leadership Style and Job Satisfaction among Nurses. Master of Human Resource Management University Utara Malaysia.

Tolentino RC. 2013. Organizational commitmentand job performance of the academic and administrative personel. International Journal of Information Technology and Business Management (JITBM) 15(1): 51-59.

Virgiawan AR Riyanto S. Endri E. 2021. Organizational Culture as a Mediator Motivation and Transformational Leadership on Employee Performance. Academic Journal of Interdisciplinary Studies 10(3): 6-79.

Vizano NA, Sutawidjaya AA, Endri E. 2021. The Effect of Compensation and Career on Turnover
Intention: Evidence from Indonesia. Journal of Asian Finance, Economics, and Business, 8(1), 471-478.

Voon ML, Lo MC, Ngui KS, Ayob NB. 2011. The İnfluence Of Leadership Styles on Employees' Job Satisfaction in Public Sector Organizations in Malaysia. International Journal of Business, Management and Social Sciences 2(1): 24-32.

Wahyuni AS, Zaika Y, Anwar R. 2014. Analisis factorfaktor yang mempengaruhi Turnover Intention (Keinginan Berpindah) Karyawnan pada Perusahaan Jasa Konstruksi. Jurnal Rekayasa Sipil 8 (2):85-95

Yunita NKL, Surya MS. 2015. Pengaruh Keadilan Organisasi dan Lingkungan Kerja Terhadap Turnover Intention. E-Jurnal Manajemen Unud 4(5): 1166-1185

Yunus A, Ahmad AB. 2013. Pengaruh Disiplin Kerja, Motivasi, Kepemimpinan terhadap Kepuasan Kerja Karyawan (Studi pada PT. Bumi Barito Utama Cabang Banjarmasin). Jurnal Wawasan Manajemen 1(2): 167-189.

Xiancheng W. 2010. An analysis of the cause of employee turnover intention in hotels. IEEE Journal 3(3): 5326-5329. 